\title{
A pulsatile swelling on the left forearm
}

\author{
Takashi Shiga • Ayman Yassa $\cdot$ Kika Dudiak • \\ Annie Sadosty
}

Received: 1 May 2009/Accepted: 21 March 2010 /Published online: 20 May 2010

(C) Springer-Verlag London Ltd 2010

A 69-year-old woman with a history of valve replacement for her aortic stenosis presented with the chief complaint of left arm pain, fever, chills, and fatigue. No recent dental procedures had been performed. However, she had undergone a colonoscopy for gastrointestinal bleeding 2 months prior to this visit. Her physical examination was notable for pyrexia, a left forearm ecchymosis, and a pulsatile $3-\mathrm{cm}$ swelling on the ulnar aspect of her arm. An ED-based ultrasound was performed, and a confirmatory study by radiology was obtained.

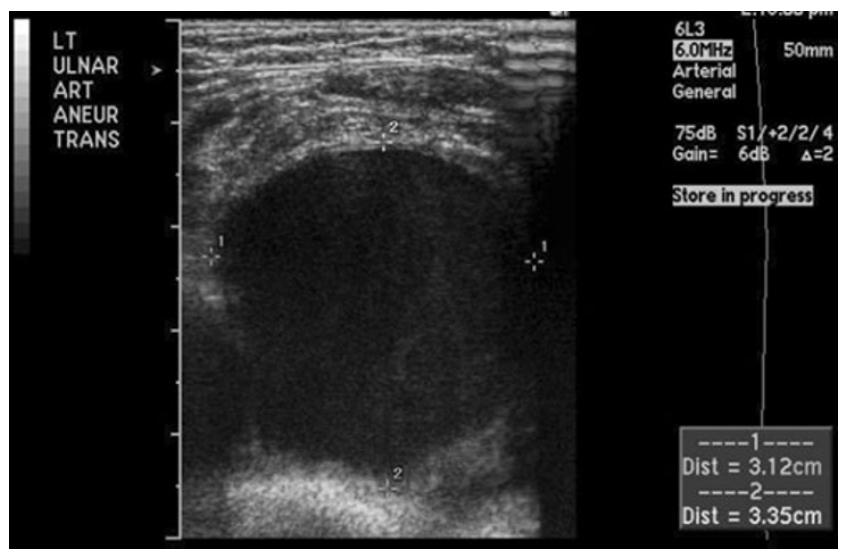

T. Shiga $(\bowtie) \cdot$ A. Yassa

Mayo School of Graduate Medical Education,

2001 st SW,

Rochester, MN 55905, USA

e-mail: xcigarx@mb.infoweb.ne.jp

K. Dudiak $\cdot$ A. Sadosty

Mayo Clinic College of Medicine,

Rochester, MN 55905, USA

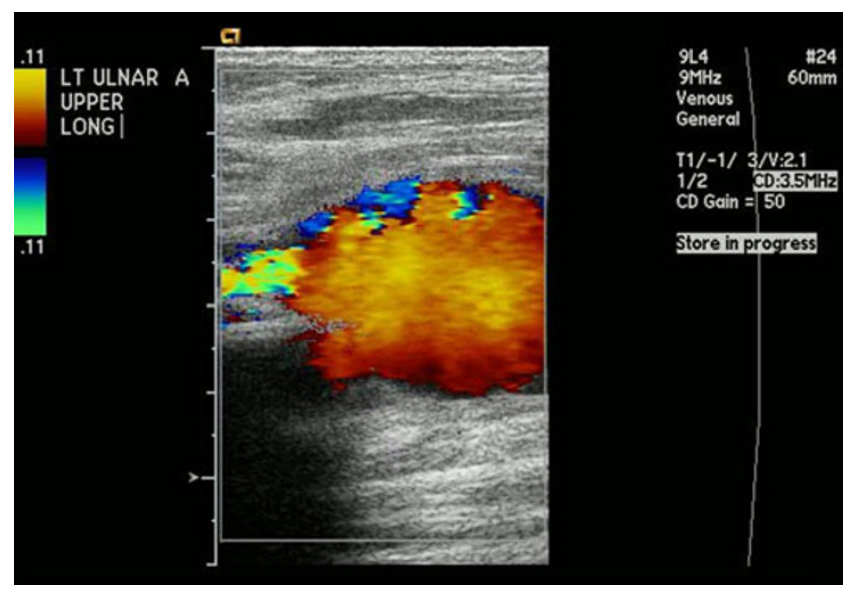

Her ultrasound demonstrated a 4-cm aneurysm arising within the left ulnar artery with intraluminal thrombus. She was found to have Streptococcus viridans infectious endocarditis and a perivalvular abscess involving her aortic valve.

Mycotic aneurysm is a rare but serious clinical disease with morbidity and mortality. The etiology of mycotic aneurysms is bacterial infection of a normal arterial wall or through secondary infection of a preexisting aneurysm [1, 2]. Commonly such aneurysms involve proximal arteries such as the aorta, iliac/femoral artery, superior mesenteric, carotid or brachial arteries [2].

Risk factors for mycotic aneurysm include trauma, bacterial endocarditis, local infection, impaired immunity, and age [1-3].

Although it is common to have Streptococcus viridansorigin infectious endocarditis, mycotic aneurysm caused by Streptococcus viridans is not common. The common 
organisms are Staphylococcus spp., Salmonella spp., Treponema pallidum, and Mycobacterium tuberculosis [1,2].

If a mycotic aneurysm is suspected, it is important to evaluate the patient for endocarditis and concurrent aneurysms [2]. This patient developed a subarachnoid hemorrhage from her coexisting anterior cerebral artery aneurysm with suspected mycotic origin [4]. After coiling the cerebral aneursym, her ulnar artery aneurysm was excised. Two months after her original presentation, she had an aortic valve replacement because of the mobile vegetation on the prosthetic valve.

\section{References}

1. Johnson JR, Ledgerwood AM, Lucas CE (1983) Mycotic aneurysm. New concepts in therapy. Arch Surg 118(5):577-582

2. Brown SL, Busuttil RW, Baker JD, Machleder HI, Moore WS, Barker WF (1984) Bacteriologic and surgical determinants of survival in patients with mycotic aneurysms. J Vasc Surg 1(4):541-547

3. Johansen K, Devin J (1983) Mycotic aortic aneurysms. A reappraisal. Arch Surg 118(5):583-588

4. Peters PJ, Harrison T, Lennox JL (2006) A dangerous dilemma: management of infectious intracranial aneurysms complicating endocarditis. Lancet Infect Dis 6(11):742-748 